\title{
Representações regionais em Carlos Gardel e Carmen Miranda
}

\section{Regional representations in Carlos Gardel and Carmen Miranda}

Alessander Kerber

No presente artigo, proponho uma análise das representações regionais presentes nas canções interpretadas por Carlos Gardel e Carmen Miranda no período entre guerras, bem como de suas relações com as identidades nacionais argentina e brasileira. ${ }^{1}$

Desde o início da formação do Estado Nacional, Brasil e Argentina passaram por situações distintas quanto à articulação deste com suas diversas regiões. No Brasil, até a década de 1930, era possível dividir as representações que definem os regionalismos em dois grupos: um primeiro, formado pelas diversas regiões do espaço mais "civilizado" da nação, ou seja, as regiões próximas ao litoral, onde estavam as maiores cidades; um segundo, formado pelo interior fraca-

Alessander Kerber é professor adjunto do Departamento de História e do Programa de Pós-Graduação em História da Universidade Federal do Rio Grande do Sul (UFRGS), Brasil (alekerber@yahoo.com.br). Artigo recebido em 20 de maio de 2009 e aprovado para publicação em $1^{\circ}$ de outubro de 2009. 


\section{Alessander Kerber}

mente povoado. Tanto em um quanto em outro grupo era difícil a definição de uma unidade nacional. Amado (1995: 145-152) compara a questão da conquista do oeste nos Estados Unidos e no Brasil afirmando que, no primeiro caso, o mito fundador da nacionalidade está associado, justamente, à integração das regiões do oeste à nação. No caso brasileiro, porém, este oeste é representado por dois espaços simbólicos: o sertão e a Amazônia. Os dois têm um caráter regional que não foi assimilado ao discurso fundador da nacionalidade.

$\mathrm{Na}$ Argentina, até em torno de 1870, toda a parte sul ainda não havia sido conquistada para a nação. Isso ocorreu com a expedição de Roca, a partir da qual se teve que pensar a integração desta região à nação. Conforme Silva,

encontramos, no século XIX, na Argentina, a experiência da fronteira gerando o inverso da tese turneriana [refere-se ao trabalho de F. J. Turner sobre a conquista da fronteira na história dos Estados Unidos], um mito negativo, na literatura acadêmica e na cultura popular. A fronteira foi vista como um lugar brutal, onde prevalecia a lei do mais forte e a justiça só poderia ser imposta de fora através da ação de representantes legais de instituições sediadas em centros urbanos distantes. Os intelectuais argentinos, ao invés de considerarem como Turner que a fronteira regenerava os costumes carcomidos da velha Europa, achavam que a luz só poderia vir de lá e que, portanto, não era o declínio da influência europeia que se devia enaltecer, mas sim o seu incremento (Silva, 2003: 12).

O processo imigratório, desencadeado especialmente a partir do final do século XIX, também serviu, conforme Martinez, Etchegaray e Molinari, para aprofundar a divisão regional do país, pois se situou especialmente nas zonas urbanas (indicando que, diferentemente do caso dos Estados Unidos, a política oligárquica dificilmente permitiu aos imigrantes o acesso à terra). São interessantes os apontamentos estatísticos apresentados pelos autores:

(...) hacia los finales del siglo XIX, el área capitalina poseía una mayoría de población extranjera (52\%), la provincia de Buenos Aires un 30\%, Santa Fe un 40\%, y Entre Ríos, Córdoba y Mendoza, alredor del $20 \%$. Mientras que las provincias del noroeste apenas si llegaban a un 2 o 3\% de extranjeros. Una excepción era Jujuy con un alto porcentaje de extranjeros, pero no de origen europeo sino boliviano. (Martinez, Etchegaray e Molinari, 2000: 161) 
No Brasil, diferentemente da República Velha, que teve o federalismo como característica, a política que se instalou após a Revolução de 1930 tendeu ao centralismo e, consequentemente, valorizou a identidade nacional em detrimento das regionais. O modelo de Estado autoritário que começava a se instaurar a partir de então teve uma importante atuação, em nível cultural, para a construção de uma nova identidade nacional. Capelato, que analisa a influência das ideias fascistas nos regimes de Vargas e Perón, afirma que elas circularam pela América Latina entre as décadas de 1930 e 40, influindo, especialmente, em dois aspectos: no desenvolvimento do nacionalismo e na emergência do estado autoritário que atuou mais sobre a cultura nacional (Capelato, 1991: 51-63).

Consideramos as trajetórias musicais de Carmen Miranda e de Carlos Gardel como vias privilegiadas para a análise das identidades nacionais brasileira e argentina. Eles foram os cantores populares de maior sucesso dentro de seus respectivos países. Além disso, não se restringiram apenas às fronteiras das nações das quais se tornaram representantes, mas tiveram, também, grande sucesso internacional, construindo um imaginário internacional acerca do Brasil e da Argentina. Como grandes ídolos populares, divulgavam ideias, símbolos e estereótipos, que eram consumidos por grande parte da população. ${ }^{3}$

Dessa forma, as fontes utilizadas para esta pesquisa são as canções gravadas por Carmen e Gardel, em número de 281 e 930, ${ }^{4}$ respectivamente. Como fontes secundárias, analiso também os filmes que contaram com a participação de ambos, os quais dão importantes subsídios sobre a imagem e a performance destes artistas. ${ }^{5}$

Quanto à cronologia deste trabalho, é necessário levar em consideração que a trajetória artística de Gardel se inicia aproximadamente uma década e meia antes da de Carmen. Além disso, a trajetória que será analisada, no caso de Carmen, estende-se até meia década após a morte de Gardel. Esta diferença de datas não impossibilita, porém, a comparação entre estes casos, levando-se em consideração a perspectiva da história comparada em sua exigência de similitudes profundas entre as sociedades enfocadas, como já afirmava Bloch (1963: 19), que definia como necessário, na escolha de sociedades para comparação, que elas fossem ao mesmo tempo vizinhas e contemporâneas, constantemente influenciadas umas pelas outras, sujeitas em seu desenvolvimento, devido à sua proximidade e à sua sincronização, à ação das mesmas grandes causas, e remontando, ao menos parcialmente, a uma origem comum. ${ }^{6}$

Esta diferenciação cronológica justifica-se tanto pela trajetória artística de Gardel e Carmen, quanto pelo contexto histórico específico em que se inserem os dois artistas, tendo em vista que houve, na Argentina, um desenvolvimento e massificação dos meios de comunicação de massa um pouco anterior ao caso brasileiro. Houve ainda uma diferença cronológica entre Argentina e Brasil 
em relação ao processo de emergência política de segmentos sociais excluídos, podendo ser tomadas, como marcos neste processo, a vitória eleitoral de Hipólito Yrigoyen, em 1916, e da Revolução de 1930, respectivamente. Essa transformação no Estado tem influência sobre as lutas simbólicas no processo de definição das representações das identidades nacionais. Além disso, essa demarcação cronológica, na qual se insere a trajetória artística analisada de Carmen e Gardel, encontra-se dentro do período entre-guerras (1918-1939). Hobsbawm (1990: 159) situa o período de apogeu dos nacionalismos no mundo entre 1918 e 1950, ou seja, justamente entre o final da Primeira Guerra Mundial e o final da Segunda, período dentro do qual está compreendido este trabalho. Esse período engloba a trajetória de Carmen e Gardel dentro de seus respectivos países.

Para este estudo, baseei-me, especialmente, nos conceitos de representação e identidades nacionais e regionais, como propõe Chartier (1990:17) ao afirmar que as lutas de representações têm tanta importância quanto as lutas econômicas para compreender os mecanismos pelos quais um grupo se propõe a impor sua concepção de mundo e seu domínio.

Uma identidade ${ }^{7}$ se expressa, justamente, através de representações que definem a ideia e o sentimento de pertencer a um grupo. Assim, ela é, ao mesmo tempo, sentimento e ideia, é sentida e pensada como formulação de uma imagem de si mesmo, ou seja, como autorrepresentação. Essa consciência de si através de representações impõe limites às práticas sociais. Estes limites se dão em torno das fronteiras entre um grupo e outro.

Uma identidade nacional se forma através de um sentimento e ideia de pertencimento a uma nação. Adotamos a definição de Anderson (1989: 14-16), que a define como uma comunidade política imaginada como limitada e soberana. Esta comunidade imaginada se identifica a partir de uma série de símbolos. Segundo Thiesse (2001/2002: 8-9), existe uma "check list", um código de símbolos internacionais, que define o que todas as nações devem ter, como: uma história estabelecendo a continuidade da nação; uma série de heróis modelos dos valores nacionais; uma língua; monumentos culturais; um folclore; lugares memoráveis e uma paisagem típica; uma mentalidade particular; identificações pitorescas - costumes, especialidades culinárias ou animal emblemático. Estes símbolos não são apenas uma lista superficial de adornos, mas são também essenciais para a autorrepresentação das pessoas que se identificam com a nação.

O contexto em estudo apresenta os meios de comunicação de massa como um elemento fundamental na construção de identidades. Esses meios têm uma grande importância, no sentido de difundir massivamente diversas representações. As lutas simbólicas em torno da construção da identidade nacional dos dois países tiveram os meios de comunicação de massa, emergentes no Brasil e na Argentina exatamente nesse período, como espaço privilegiado. 
No Brasil, as primeiras experiências com rádio datam de 1922, e a sua massificação se inicia na década de 1930, justamente o período varguista, enquanto, na Argentina, essa massificação se deu anteriormente, associada ao poder de consumo da sociedade argentina. Conforme Haussen,

$\mathrm{Na}$ Argentina (...) a indústria de equipamentos radiofônicos desenvolveu-se mais velozmente que a brasileira, bem como o contexto socioeconômico e cultural era diverso. (...) No final da década de 20, havia no Brasil 19 emissoras em funcionamento enquanto que na Argentina, um país com um número bem menor de habitantes e com uma extensão territorial inferior à brasileira, 36 emissoras já estavam instaladas. E não era só no número que se estabelecia a diferença: esta ocorria também na publicidade, na tecnologia e no conteúdo.

Enquanto no Brasil a programação de cunho educativo e cultural permaneceu por mais tempo, com as emissoras sendo constituídas como radioclubes ou rádio-sociedades, na Argentina a influência da publicidade começou bem mais cedo. (...) já em dezembro de 1922 surgia a primeira emissora comercial, a "LOX Rádio Cultura", de Buenos Aires. (Haussen, 2001: 25)

Enquanto, na Argentina, a rádio comercial já existia na década de 1920, no Brasil, a regulamentação para a propaganda veio apenas com a época de Vargas, em 1932. Foram justamente os anos 1930 que assistiram, no Brasil, à emergência deste novo meio de comunicação de massa.

Ao lado do rádio, o gramofone auxiliou na difusão e massificação da música. Carmen e Gardel também foram os primeiros maiores vendedores de discos do Brasil e da Argentina. Como os aparelhos de rádio, os gramofones chegaram inicialmente às casas das elites e, no decorrer da década de 1930, passaram por um processo de relativa massificação, apesar de nunca terem chegado aos níveis de vendas do rádio.

O desenvolvimento do rádio foi fundamental na construção dessa nova identidade, tendo sido utilizado largamente pelo Estado para esse fim. O potencial desse meio é afirmado na canção "Cantores de rádio", marcha de Alberto Ribeiro, Josué de Barros e Lamartine Babo, interpretada por Carmen e Aurora Miranda (sua irmã), em 1936, numa estrofe que expressa muito bem sua influência.

Nós somos as cantoras do rádio

Nossas canções cruzando o espaço azul

Vão reunindo num grande abraço

Corações de norte a sul 
O poder desse meio de comunicação está associado à grande distância que poderia alcançar num mesmo instante. Isto ia ao encontro da necessidade da política getulista de unir, simultaneamente, "corações de norte a sul”, ou seja, unir a nação, fazen do com que a própria voz de Vargas e a de cantores, como Carmen Miranda, fossem ouvidas por todas as regiões do Brasil.

Encontram-se nas músicas e imagem de Carmen e Gardel vários signos que representam o Rio de Janeiro e Buenos Aires. Um elemento importante desta representação era o uso da gíria. Enquanto Gardel utilizava, tanto nas letras de suas músicas como, mesmo, em sua fala, o lunfardo, a gíria portenha, Carmen esbanjava gírias que havia aprendido em sua infância e primeira juventude no bairro da Lapa, o bairro boêmio do Rio de Janeiro no qual ela residiu.

Contudo, apesar dessa identificação com ambas as cidades, Carmen e Gardel buscaram representações de outras identidades regionais na construção de suas imagens. Mais especificamente, Carmen ficou consagrada como baiana, enquanto Gardel, em grande medida, utilizou a imagem do "gaucho", ligada ao interior argentino. Eles se utilizaram de vestimentas consideradas típicas dessas regiões (Gardel em seu início de carreira e em algumas apresentações, principalmente na Europa e, Carmen, a partir de 1938). Esta escolha de ambos os artistas também está associada ao processo de negociação sobre a identidade nacional existente na época e, além de haver identidades regionais envolvidas nela, havia também questões de definição da nação entre elites e segmentos populares, de tal modo que tanto o "gaucho" quanto a baiana, vendendo suas comidas típicas, representam identidades populares de suas respectivas regiões.

Faço, porém, uma distinção entre os casos de ambos os artistas. A imagem de Carmen Miranda que ficou consagrada foi, especificamente, a de baiana. Gardel, apesar de ser lembrado também como "gaucho", tem, ainda mais marcante, sua imagem utilizando smoking ou outras roupas que representam as identidades de elite argentina, especialmente de Buenos Aires. Também, diferentemente do caso de Carmen, Gardel, na Argentina, tornou-se um consenso quase que absoluto em termos de adoração e legitimidade como representante nacional. Isso, em grande medida, deve-se ao fato de ele apresentar, em sua vestimenta, representações ora populares, ora de elite, ora do interior argentino (mais associado à região pampeana), ora da grande cidade.

A vitória simbólica das representações da Bahia, através de Carmen Miranda, deu-se a partir de 1938, num momento fortemente influenciado pela aversão estatal à figura do malandro, representante do Rio de Janeiro. Nesse ano, foi gravado "O que é que a baiana tem", um samba baiano típico de Dorival Caymmi, que, além de compositor, também ajudou Carmen a montar seu figurino de baiana e participou da gravação da música para o filme Banana da Terra: 
Figura 1

A imagem de baiana construída por Carmen em 1938 (Barsante, 1983: 10)

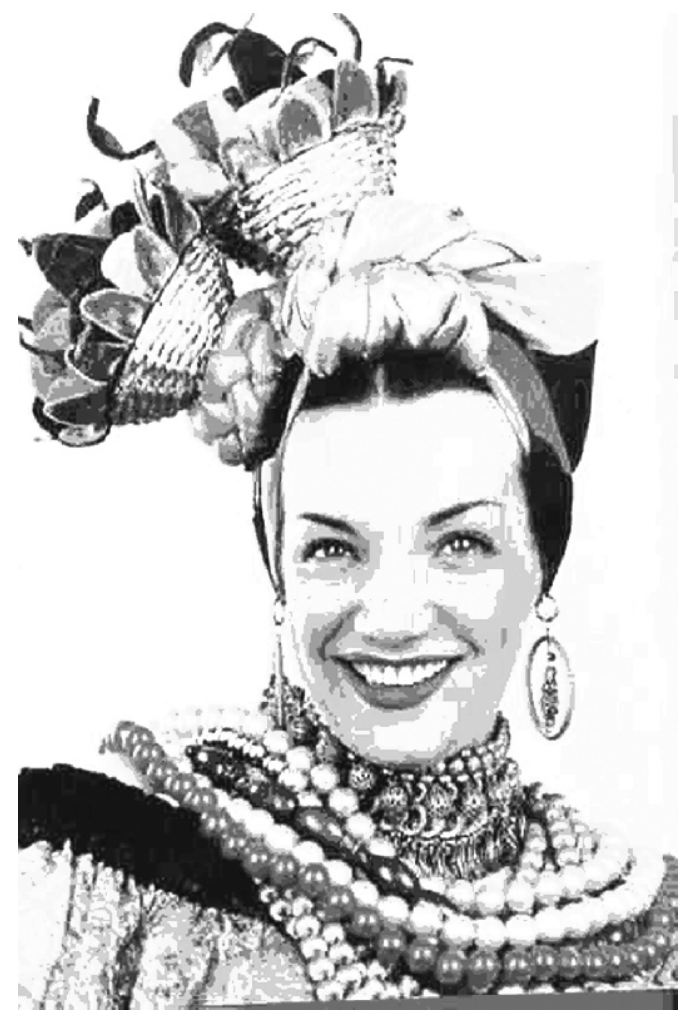

CM: O que é que a baiana tem?

Coro: $\mathrm{O}$ que é que a baiana tem?

CM: Tem torso de seda, tem (tem)

Tem brinco de ouro, tem (tem)

Corrente de ouro tem (tem)

Tem pano da Costa, tem (tem)

Tem bata rendada, tem (tem)

Pulseira de ouro tem (tem)

Tem saia engomada, tem (tem)

Tem sandália enfeitada, tem (tem)

E tem graça como ninguém

Coro: O que é que a baiana tem?

CM: Como ela requebra bem

(...) 
É certo que o poder simbólico de Carmen influiu na legitimação da baiana como símbolo nacional. Contudo, existem outros elementos que também deram legitimidade à baiana. Em primeiro lugar, temos de levar em conta que foi em terras do atual estado da Bahia que os primeiros portugueses chegaram ao Brasil, e que Salvador foi, durante grande parte do período colonial, capital. Neste sentido, a Bahia já fazia parte do imaginário de amplos segmentos da população brasileira dos anos 1930 como o local da origem do Brasil, o "mito fundador" (Chaui, 2000) da nacionalidade. A data da chegada de Pedro Álvares Cabral a terras que, nos anos 1930, pertenciam ao estado da Bahia se tornara feriado nacional e, consequentemente, representação muito difundida como marco inicial da nacionalidade brasileira.

Além desses elementos, presentes no discurso histórico e largamente difundidos entre amplos segmentos da população, havia, dentro da composição urbana do próprio Rio de Janeiro, um importante elemento legitimador dos símbolos da Bahia como representantes do nacional. Como analisa Velloso (1990), houve, especialmente durante a República Velha, uma grande migração de baianos para essa cidade. Baianos que chegaram ao Rio de Janeiro puderam manter vários elementos de sua cultura, por exemplo, nas casas das famosas "tias baianas".

Dessa forma, já havia uma certa receptividade, entre setores da capital do país, à legitimação de símbolos baianos como nacionais. Assim, se poderia afirmar que a legitimação desses símbolos esteve intimamente associada ao aval recebido no Rio de Janeiro. Além disso, essa "vitória" simbólica da baiana também teve influência da indústria cultural norte-americana, que escolheu a imagem da baiana de Carmen como símbolo do Brasil quando ela foi para os Estados Unidos, como analisa Garcia (2004).

Pelo lado da política, especialmente quanto à valorização do trabalho proposta pelo Estado durante o governo Vargas, poderíamos fazer mais uma inferência sobre a figura da baiana como representante do nacional. Ao contrário do malandro, a baiana não representa um mundo à margem do trabalho regular.

A imagem de baiana construída por Carmen não foi, contudo, uma cópia fiel das baianas que vendiam comidas em Salvador. Ela selecionou alguns elementos dos trajes dessas baianas e acrescentou outros, como analisaremos mais tarde. Foi algo muito chocante para a época: uma cantora que sempre havia se vestido dentro das tendências da moda urbana do Rio de Janeiro, nesse momento, construiu um figurino totalmente distinto. Mais impressionante ainda foi o resultado disso. Segundo a biógrafa Gil-Montero, após a estreia de Banana da Terra, grande parte dos que participavam dos desfiles de carnaval nas ruas do Rio usavam uma baiana - não bem o clássico traje baiano, mas a nova versão de Miranda. Em outras palavras, a imagem transmitida foi acolhida pelos receptores, tendo a representação atingido seus objetivos. 
Como analisei em artigo intitulado "Carmen Miranda entre representações da identidade nacional e de identidades regionais" (Kerber, 2005), a figura da baiana também vai ao encontro da questão étnica da miscigenação, especialmente entre a negra e a branca que, nela, se fundem harmoniosamente, como propunha Gilberto Freyre. O pano da Costa, que lembrava a herança africana, o Bonfim, que lembrava o Candomblé, logo após o rosário de ouro, que lembrava a Igreja Católica. Enfim, a baiana seria a representação que melhor expressaria esta forma de síntese do Brasil. E, importante, uma síntese harmônica, que representava as camadas populares brasileiras em convívio pacífico com as elites.

Contudo, não podemos esquecer que a figura da baiana apresentada por Carmen Miranda não era idêntica à original da Bahia, mas uma montagem em que ela uniu o seu gosto para roupas com a orientação dada por Dorival Caymmi. Assim, Carmen fez uma série de alterações na figura da baiana (ver figura 1): fios de contas no pescoço, o estômago nu, muitos "balangandãs", o uso de muitas cores vistosas, e um turbante com duas cestinhas cheias de frutas.

Fazendo uma leitura dessa imagem, podemos associá-la com a questão das identidades regionais. $\mathrm{O}$ colorido, associado às nossas belezas naturais, e as cestinhas de frutas na cabeça remetem à pujança da natureza brasileira. Chauí identifica "a sagração da natureza" como um dos elementos do mito fundador da identidade nacional brasileira. Este elemento tem sua construção já nas primeiras narrativas produzidas pelos europeus sobre as terras americanas. Carmen parece se ligar a esse mito fundador. Sua imagem de baiana é marcada pelo exagero de cores que culminam com a famosa cesta de frutos na cabeça. Quase que poderíamos associá-la à imagem do "paraíso terrestre" com sua "vegetação luxuriante e bela".

A baiana, como o próprio nome desta figura diz, não deixou de ser um símbolo regional, mas as alterações feitas pela cantora deram a ela a possibilidade de, além disso, também ser nacional. É evidente que o cinema norte-americano dos anos 1940 foi responsável pela consagração, especialmente para a posteridade, da imagem de baiana criada por Carmen. Contudo, as representações precisam ter receptividade para se legitimarem, e esta receptividade pode ser explicada, pelo menos em parte, dentro do contexto do Brasil dos anos 1930.

No caso de Gardel, tal como no de Carmen, a imagem utilizada de "gaucho" vinha ao encontro tanto da necessidade de afirmação de segmentos populares quanto da mistura de elementos simbólicos que poderiam ser tomados como uma síntese nacional. Carmen não era baiana, não vendia acarajé, nem era negra, mas a assimilação destes elementos, e de outros criados pela própria cantora, apresentavam-se como uma versão da identidade nacional. 
Carlos Gardel também tinha esse projeto de ser argentino. No filme Rosas de Otoño, gravado por Gardel em 1930 e dirigido por Eduardo Morera, por exemplo, o cantor tem uma atitude que parece ser um "prestar contas", para seu público, de sua atuação internacional. Ao ser cumprimentado e perguntado como está, responde, olhando para a câmera, ou seja, para o público: "Como siempre Hermano: dispuesto a defender nuestra lengua, nuestros costumbres y nuestras canciones (...)". O interlocutor ainda enfatiza que ele está fazendo o possível para que "nossas canções" sejam conhecidas no mundo inteiro.

Essa atitude de Gardel indica que havia, em seu caso, tal qual no de Carmen, uma intencionalidade em se mostrar para o público como representante nacional. Para tanto, ele misturou sua trajetória pessoal ${ }^{8}$ e musical, que trazia elementos simbólicos dos grupos populares e de elite de Buenos Aires, com a imagem que representava os grupos populares do interior da Argentina: o "gaucho". Em diversas de suas canções, Gardel descreve o "gaucho" em seu espaço, na paisagem idealizada do campo que compõe o "mito fundador" da identidade nacional argentina, como no tango “ ¿Pa' que más?” de José Ceglie, com letra de Atilio Supparo, gravado em 1926, ou na canção "De mi tierra", de Pedro Numa Córdoba, Francisco Lozano e Eduardo Manella, gravado por Gardel em 1921:

En la pampa de mi tierra, bellas flores y praderas, de un aroma y hermosura sin igual mi ranchito allá lejano, nido de toda mi raza, lo que el tiempo su recuerdo borrará.

En el puente de junquillos que atraviesa el manso arroyo cuantas veces me he parado para oír el murmullo de las aguas, el cantar de los troperos y de chinas y paisanos sonreir...

Conforme Archetti (2003), a Argentina, sob o impacto de uma maciça imigração europeia, precisou reconfigurar sua identidade nacional. Nesse contexto, as tradições e vestimentas "gauchas" constituíram elementos-chave de um revivescimento nacionalista. O autor analisa a vestimenta "gaucha" em sua relação com a identidade nacional argentina. Num momento em que a Argentina era tomada por uma imigração em massa e em que se impunha uma diversidade cultural vasta, a imagem antiga do "gaucho" se apresentava como um refúgio e, mesmo, uma saída para se pensar a imagem do argentino. A imagem do "gaucho", oriunda dos grupos populares do interior, e o estilo musical tango, oriundo dos grupos populares da cidade mas aceitos também pelas elites desde seu sucesso no exterior, misturaram-se nas primeiras décadas do século XX para representar a Argentina como um todo. 


\section{Figura 2}

Gardel no filme El día que me quieras, de 1935 (Barsky e Barsky, 2004)

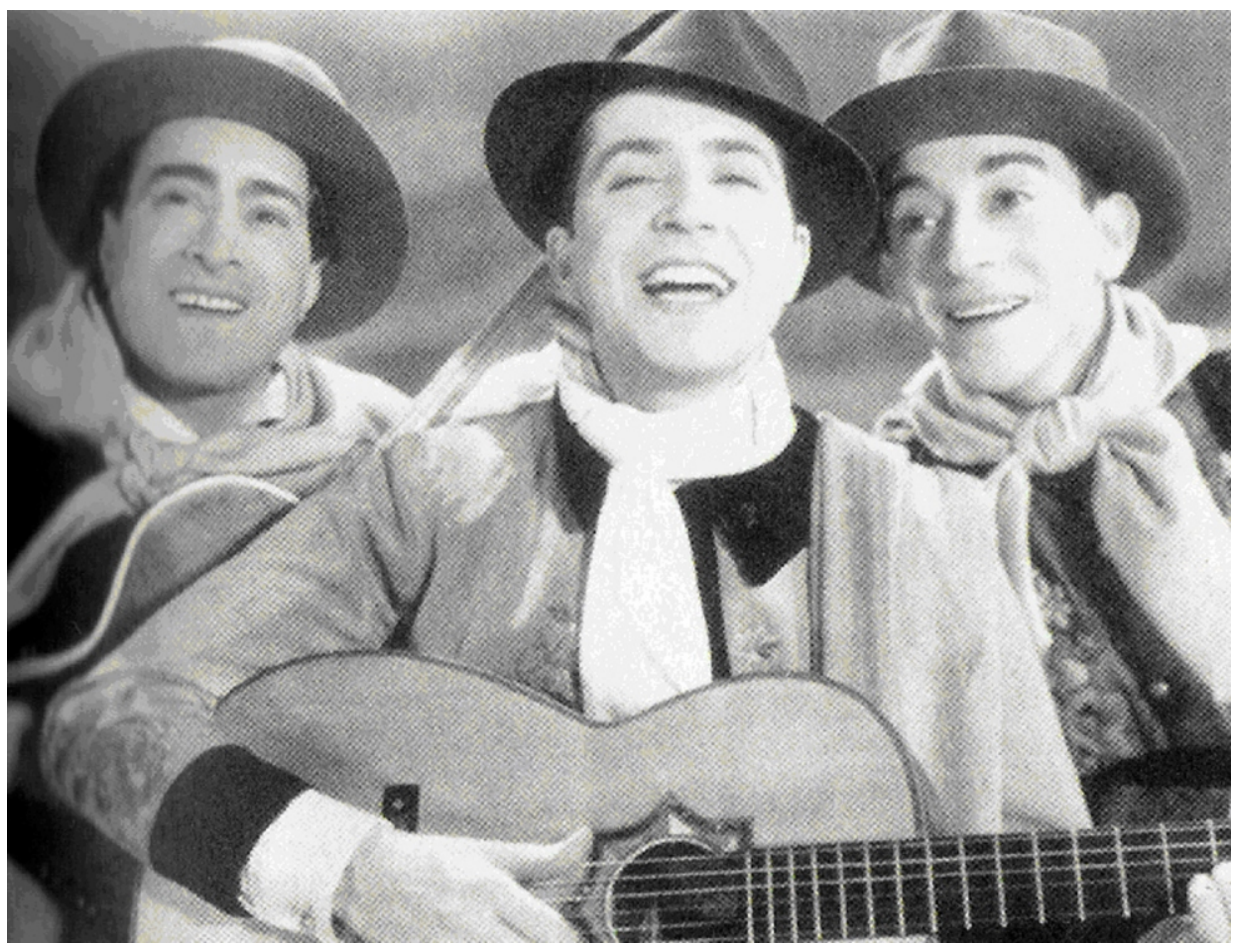

Apesar de não apresentar uma quantidade de adornos em seu figurino como fazia Carmen, também existe uma composição nas roupas de Gardel que pode ser analisada em sua relação com as identidades regionais e nacional. Pode-se afirmar que, mesmo ele também tendo uma certa diversidade em seu figurino, há duas imagens que se consagraram: a do "gaucho" e a do homem sofisticado de Buenos Aires.

A imagem, do filme El día que me quieras, de 1935, retrata o "gaucho".9 Contudo, há uma série de elementos que lembram o homem sofisticado de Buenos Aires. Perceba a diferença entre seu chapéu e o dos outros integrantes da imagem. O chapéu usado por Gardel não é o tradicional, mas é o cosmopolitamente presente, nos anos 1930, nas ruas de grandes cidades, como Paris, Nova Iorque e... Buenos Aires.

Também, percebe-se que o lenço amarrado no pescoço, peça típica da indumentária do "gaucho", diferentemente dos outros dois "gauchos" da imagem, 
está amarrado para o lado. Se não houvesse esses dois outros "gauchos" com lenço no pescoço, quem visualizasse essa imagem provavelmente ficaria em dúvida se tratava-se de um lenço "gaucho" ou de um cachecol, comumente usado por homens sofisticados de vários países de clima frio.

Neste sentido, poder-se-ia afirmar que, tal como Carmen Miranda, Carlos Gardel construiu uma imagem misturando elementos de distintas identidades com o intuito de tornar-se a síntese delas. Em relação às identidades regionais, Carmen, ao tentar construir uma síntese sobre o Brasil, mistura símbolos que representam a identidade regional da Bahia com outros, que representam o Rio de Janeiro, contendo, ainda, elementos de caráter não-regional. Gardel, por sua vez, faz a síntese da antiga oposição entre a cidade de Buenos Aires, representada pela moda e os padrões europeus, e o campo, representado pelo "gaucho", a síntese entre a "civilização e a barbárie".

$\mathrm{Na}$ construção social de significado para uma determinada gravação, a letra da música é indissociável da imagem do seu intérprete. No caso das letras das canções interpretadas por Carmen e Gardel, parece que elas vêm complementar sua imagem, apontando, também, para elementos mais específicos que a imagem em si não apresenta.

Existe, como vimos, um conflito regional na construção das nações brasileira e argentina, e, consequentemente, identidades regionais estão presentes nas lutas simbólicas que envolvem a negociação das identidades nacionais. Essa negociação também se expressa nas letras das canções interpretadas por Carmen e Gardel. Apesar de assimilarem elementos simbólicos de algumas regiões específicas, tanto Carmen quanto Gardel tomam o cuidado de não se colocar em oposição a outras regiões.

Também é tendência geral, tanto de Carmen quanto de Gardel, tentarem a construção de uma identidade nacional que seja composta por uma harmônica combinação entre as diversas regiões. Esta tendência se expressa mais ainda no final dos anos 1930, provavelmente por influência das ideias fascistas. Existe, nesse momento, uma pressão política maior para evitar quaisquer oposições identitárias internas à nação, mobilizando as energias em prol desta identidade única. Por exemplo, já em pleno auge da censura política do DIP(Departamento de Imprensa e Propaganda), em 1940, Carmen gravou "Recenseamento", de Assis Valente, em que canta:

(...) Obediente, sou a tudo o que é de lei

Fiquei logo sossegada e falei então

O meu moreno é brasileiro, é fuzileiro

E é quem sai com a bandeira do seu batalhão

A nossa casa não tem nada de grandeza 
Mas vivemos na pobreza sem dever tostão

Tem um pandeiro, tem cuíca e um tamborim

Um reco-reco, um cavaquinho e um violão

Fiquei pensando e comecei a descrever

Tudo, tudo de valor que meu Brasil me deu

Um céu azul, um Pão-de-Açúcar sem farelo

Um pano verde-amarelo

Tudo isso é meu

Tem feriado que pra mim vale fortuna

A Retirada de Laguna vale um cabedal

Tem Pernambuco, tem São Paulo e tem Bahia

Um conjunto de harmonia que não tem rival

A letra desse samba remete ao discurso oficial, que tentava restringir as rivalidades regionais, pensando essas identidades como um "conjunto de harmonia". Conforme Paranhos, apesar do intervencionismo e da censura estatal, houve espaço para que outras versões sobre a nação brasileira fossem construídas, driblando a censura mesmo em seu auge, a partir de 1940, o que mostra a diversidade de agentes envolvidos na negociação sobre essa identidade. Como ele afirma:

Sem pretender negar a adesão espontânea, forçada ou interessada de muitos compositores populares à cantilena estado-novista, o que se percebe, em dezenas de registros fonográficos do período, é que, apesar dos pesares, o coro dos diferentes jamais deixou de se manifestar, de modo mais ou menos sutil, conforme as circunstâncias. (Paranhos, 2002: 91)

Esta canção nos mostra que, mesmo não sendo ideia consensual, uma moça pobre da época sabia que se propunham as representações de diversas regionalidades como harmonicamente unidas para compor a nação e afirmava isso para o "agente recenseador", com o provável intuito de dizer o que ele queria ouvir, já que ele estava esmiuçando sua vida, o que foi “um horror”. É nesse sentido que Pernambuco, São Paulo e Bahia são apresentados por ela ao agente não em divergência com o Brasil, mas em plena harmonia com ele. E estes três estados não foram escolhidos aleatoriamente para serem citados. Eles representam extremos da diferença cultural entre as regionalidades brasileiras.

Essa ideia de harmonia, que uniria as diversas regiões do país, como propunha-se no Estado Novo, é representada, frequentemente, nas músicas inter- 
pretadas por Carmen no final da década de 1930. É o caso de "Diz que tem", samba-batuque de Vicente Paiva e Anibal Cruz, também gravado em 1940. Esta canção parece-nos menos irônica, ao apresentar esta união harmônica das diversas regionalidades, conforme era de interesse do Estado Novo:

Cantei em São Paulo, cantei no Pará

Tomei chimarrão e comi vatapá

Eu sou brasileira, meu it revela

Que minha bandeira é verde e amarela

Temos, nessa canção, novamente, uma relação íntima entre São Paulo, Pará, Rio Grande do Sul (representado pelo chimarrão), Bahia (representada pelo vatapá) e a nação brasileira. Dá-se a ideia de que a união de todas as culturas regionais é necessária para a construção da cultura nacional, e de que a nacionalidade não exclui nenhuma regionalidade, colocando-se em primeiro plano em relação a elas.

No caso das canções interpretadas por Gardel, está presente em várias delas a ideia da mobilidade do campo para a cidade e da cidade para o campo. $\mathrm{O}$ "gaucho" vai do campo para a cidade, onde emerge junto ao tango. Num caminho oposto, o "gaucho" sente saudade do campo e retorna a ele.

Neste sentido, através da figura do "gaucho" e de sua mobilidade, unem-se, também harmoniosamente, apesar de que com sofrimento, como não poderia deixar de ser no caso do tango argentino, essas duas regióes. Gardel traz essas questões também nas letras de suas músicas, como é o caso da canção "A la luz del candil”, tango de Carlos Vicente Geroni Flores e Julio Navarrine, gravado em 1927:
¿Me da su permiso, señor comisario?
Disculpe si vengo tan mal entrazao yo soy forastero y he caido al Rosario trayendo en los tientos un guen entripao Acaso usted piense que soy un matrero yo soy gaucho honrado a carta cabal no soy un borracho ni soy un cuatrero (...)

Já no final de sua carreira, em 1935, tal qual em sua imagem, no tango "Arrabal amargo", de Gardel e Alfredo Le Pera, parece que se mistura o campo aos subúrbios de Buenos Aires, as duas regiões pelas quais o "gaucho" circularia. Ao utilizar a expressão "Rinconcito arrabalero", Gardel parece criar uma identi- 
dade entre esses dois espaços: o "rinconcito", associado ao espaço do campo, e o "arrabalero", associado ao espaço dos arrabaldes, dos subúrbios. Também em "Lejana tierra mia", canção composta por Gardel e Le Pera, gravada em 1935, o cantor fala dessa saudade de seu espaço tido como de origem:

\author{
Lejana tierra mia \\ bajo tu cielo, bajo tu cielo \\ quiero morirme un día \\ con tu consuelo, con tu consuelo (...)
}

A andorinha (golondrina) é uma representação da mobilidade e, mais do que isso, do grande espaço de circulação. Esta representação é utilizada no tango "Golondrinas", de Carlos Gardel e Alfredo Le Pera, para identificar a alma "criolla", que é errante e "viajera". Através da andorinha, as diferentes identidades regionais podem se fundir, formando a Argentina.

Outra imagem utilizada por Gardel para estabelecer a ligação entre as diferentes regiões é a do passarinho. No tango "Pajarito", de Dante A. Linyera e Francisco Bautista Rímoli, gravado por Gardel em 24 de abril de 1930, apresenta-se uma ligação mais forte ainda entre a imagem do passarinho e a integração nacional:

\author{
¡Pajarito! Que al rodar al compás del grito \\ i“Prensa", “Argentina!, "Nación”!, \\ vas cortando las aceras, \\ y flameando las banderas \\ de tu propia perdición. \\ ¡Pajarito! No olvides que con el grito \\ ¡"Prensa”, “Argentina!, "Nación”! \\ Por las urbanas arterias, \\ vas cantando tus miserias de gorrión (...)
}

Percebe-se que a imagem do passarinho se mistura com os gritos de "Prensa", "Argentina" e "Nación", quase estabelecendo o passarinho (talvez, metáfora dos meios de transporte, do deslocar-se facilmente por diversas regiões) e a imprensa (o deslocar das informações), como elementos fundamentais na construção da nação argentina.

Outro elemento importante a salientar sobre Gardel é a menção de diversas regiões em suas canções. É o caso, por exemplo, de Mendoza, retratada na canção "Claveles mendocinos", zamba de Alfredo Pelaia, gravada em 1924. Também é o caso da província de Entre Rios, retratada em "La entrerriana", valsa de 
Alfredo Eusebio Gobbi, gravada por Gardel em 21 de junho de 1927 e, ainda, fazendo referência a Tucumán, na zamba "Tucumana" de Alfredo Navarrine e Enrique Delfinom, gravada em 1924. Há, também, a referência a Córdoba, na zamba "Cordobesita", de Celedonio Flores e Samuel Castriota, gravada em 1925.

A explicação para essas gravações de Gardel parece ser muito óbvia: ele precisava se direcionar ao seu público das diversas regiões argentinas e atender este consumidor. Sendo visto como portenho, a forma de fazer isso era falar dessas várias regiões (assim como havia falado de diversas etnias) de forma elogiosa e harmoniosa.

Contudo, apesar de poder haver harmonia entre as diferentes regiões, uma nação não pode ser apenas o somatório de várias regionalidades. Ela necessita de símbolos unitários que se sobreponham aos regionais e que representem a nação em todas as suas regiões, justificando a união dos vários estados. Na busca de uma unidade nacional, ao mesmo tempo que se aceitavam as identidades regionais, era necessário encontrar símbolos unos, os quais servissem para toda a nação. Desta forma, a escolha do "gaucho" como representante nacional e sua circulação por diversas regiões, ou mesmo a utilização da representação da andorinha podem ser identificadas como formas de, no caso argentino, construir uma unidade entre diversas identidades regionais.

No caso brasileiro, a centralização política se deu no Rio de Janeiro, sendo lógico que essa região tivesse certa preferência na definição de símbolos nacionais. A partir da República, houve uma ação política que buscou apagar da paisagem urbana tudo o que lembrava o "atraso" do Império, tornando o Rio a cidade-símbolo da modernização do Brasil, ao mesmo tempo em que era, pela própria condição de capital, cidade-símbolo da nacionalidade. ${ }^{10}$ Contudo, representações de outras regiões apresentam-se, nas canções interpretadas por Carmen Miranda, como harmonicamente combinadas na composição da identidade nacional, havendo um enfoque especial, quantitativa e qualitativamente, em relação à Bahia.

\section{Notas}

1. Em minha tese de doutorado, defendida na Universidade Federal do Rio Grande do Sul e intitulada Representações das identidades nacionais argentina e brasileira nas canções interpretadas por Carlos Gardel e Carmen Miranda (1917-1940) (Kerber, 2007), analiso essas representações das identidades nacionais presentes nas músicas, imagens e performances dos artistas. Neste artigo, proponho analisar as identidades regionais e sua relação com a identidade nacional, em ambos os países, a partir do mesmo corpus documental, numa perspectiva comparada. Nesse sentido, 


\section{Representações regionais em Carlos Gardel e Carmen Miranda}

articulo questões oriundas de minha tese com o projeto de pesquisa que realizo na UFRGS intitulado "Representações musicais e mídia sonora na construção de identidades ligadas ao espaço geográfico: a nação, a região, a cidade", financiada pelo CNPq através do edital 14/2008.

2. Entre esses intelectuais que construíram uma visão negativa do interior da Argentina, um dos mais importantes foi Domingos Faustino Sarmiento (presidente entre 1868 e 1874). Seu livro clássico Facundo: civilização e barbárie - foi escrito em 1845, enaltecendo as virtudes da região civilizada - a cidade ou, em suma, Buenos Aires - exatamente no momento do governo Rosas e como crítica ferrenha a ele. A imagem do "gaucho", representação do espaço rural argentino que foi muito utilizada por Gardel, é extremamente negativa nesta obra. Ele é visto como preguiçoso, servidor do poder dos chefes locais e, ainda, como nômade, um entrave para o progresso da civilização.

3. Durante toda a década de 1930, Carmen foi a maior vendedora de discos do Brasil, superando de longe os outros cantores considerados de sucesso na época. Além disso, mais recentemente, focalizando a carreira de Carmen a partir da revista $O$ Cruzeiro, Garcia (1999: 72) constata que a cantora já era identificada, durante os anos 30 , como associada à identidade nacional, sendo chamada de "cantora do it verdeamarelo". Neste sentido, várias reportagens a vinculavam ao caráter nacional. No caso de Gardel, Peluso e Visconti, em seu livro sobre a repercussão do cantor na imprensa mundial, indicam, também, tal associação. Por exemplo, o Anuario Teatral Argentino de 1924 anunciava: "Es el dúo de cantos nacionales más popular de la República Argentina. Ellos cultivan con fidelidad e inimitable gusto, todo el cancionero típico porteño y folklorista argentino". O “dúo" referido é a parceria estabelecida, desde 1911, de Gardel com o cantor José Razzano (Peluso e Visconti, 1998: 39).

4. A busca pelas músicas interpretadas por Carmen já foi feita durante a realização de minha dissertação de mestrado. Neste artigo, utilizo as transcrições das letras das músicas presentes no trabalho de Cardoso Júnior (1978), o mais completo como conjunto de informações sobre a produção artística da cantora. No caso de Gardel, utilizo a grafia das transcrições feitas em sua Compilación poética, publicada em 3 volumes no ano de 2003 pela editora Corrigidor.

5. Necessário mencionar que Carmen e Gardel atuaram essencialmente em filmes musicais cujo momento fundamental se dava exatamente nos momentos em que interpretavam uma canção. Carmen atuou nos filmes $A$ voz do Carnaval (1933), dirigido por Adhemar Gonzaga e Humberto Mauro (Cinédia); Alô, alô, Brasil (1935), dirigido por Wallace Downey, João de Barro e Alberto Ribeiro (Waldow-Cinédia); Estudantes (1935), dirigido por Wallace Downey (Waldow-Cinédia); Alô, alô, Carnaval (1936), dirigido por Adhemar Gonzaga (Waldow-Cinédia); Banana da terra (1938), dirigido por Wallace Downey (Sonofilmes), e Down Argentine Way (1940), dirigido por Irving Cummings (Fox). Contudo, alguns dos filmes mais antigos que contaram com sua participação não existem mais. Gardel atuou, em 1930, em dez curtas, em cada um dos quais canta um número de seu repertório: Añoranzas; Cancero; Enfundá la mandolina; Mano a mano; El carretero; Padrino pelado; Rosa de otoño; Tengo miedo; Viejo smoking; Yira, Yira. Também atuou em Luces de Buenos Aires (1931), dirigido por Adelqui Millar (Paramount); Esperame (1932), dirigido por Luis Gasnier (Paramount); La casa es seria (1932), dirigido por Jaquelux (Paramount); Melodía de arrabal (1933), dirigido por Luis Gasnier (Paramount); Cuesta Abajo (1934), dirigido por Luis Gasnier 
(Paramount); El tango en Broadway (1934), dirigido por Luis Gasnier (Paramount); The big broadcast of 1935 (1935), dirigido por Norman Taurog e Theodore Reed (Paramount); En día que me quieras (1935), dirigido por John Reinhardt (Paramount), e Tango Bar (1935), dirigido por John Reinhardt (Paramount).

6. Desta forma, como propõem Cardoso e Pérez Brignolli, a história comparada consiste em buscar semelhanças e diferenças que apresentam duas séries de natureza análoga, tomadas de meios sociais distintos, atentando para a possibilidade de erros, como cometer anacronismos, exagerar as virtudes do método comparativo, cujas finalidades não incluem a ilusão meta-histórica de uma "receita", ou de um pequeno número de elementos ou fatores que permitam "decifrar" o conjunto do devir humano e confundir comparação com justaposição (Cardoso e Pérez Brignolli, 1990: 413-415).

7. Ao analisar a construção de identidades, Chartier aponta para as perspectivas que a história cultural trouxe a esta questão, diferenciadas de duas visões existentes anteriormente: uma que as via como resultado de imposições de representações e resistências contra estas, outra que as via como exibição de uma unidade construída a partir de um grupo. $\mathrm{O}$ autor afirma que "trabalhando sobre as lutas de representações, cujo objetivo é a ordenação da própria estrutura social, a história cultural afasta-se sem dúvida de uma dependência demasiado estrita em relação a uma história social fadada apenas ao estudo das lutas econômicas, mas também faz retorno útil sobre o social, já que dedica atenção às estratégias simbólicas que determinam posições e relações e que constroem, para cada classe, grupo ou meio, um 'ser-percebido' constitutivo de sua identidade" (Chartier, 2002: 73).

8. Na década de 1930, quando Carmen surgiu como grande estrela, sua origem portuguesa foi mantida em segredo. Seu comportamento e sua fala, empregando constantemente gírias das camadas populares do Rio de Janeiro, faziam com que fosse difícil alguém imaginar sua origem imigrante. Quando "vazou” a informação de que era portuguesa, um jornalista do jornal $O$ Pais lhe perguntou se ela nascera no Rio. Ela respondeu que "era filha de Portugal, embora seu coração fosse brasileiro" (Gil-Montero, 1989: 39). No caso de Gardel, quando era perguntado sobre sua real nacionalidade por algum jornalista, respondia: “'Mi patria es el tango', solía decir, o 'Soy ciudadano de la calle Corrientes"' (Collier, 1988: 91). Evidentemente, era uma forma de burlar o imaginário social que o associava à Argentina enquanto, na realidade, não havia nascido nesse país. Através de exaustivo trabalho com diversas fontes, Collier (1988) intitula o primeiro capítulo de seu livro sobre Gardel como "El niño de Toulouse". Gardel nasceu Charles Romuald Gardes, em 1890, na França, filho de Berthe Gardes e de pai desconhecido. Contudo, o imaginário social pode construir-se independentemente de documentos oficiais. Neste caso, o desejo coletivo de não identificá-lo como francês imperou e, tanto a Argentina quanto o Uruguai construíram a sua versão para o nascimento de Gardel. Estas versões tornaram-se aceitas por boa parcela da população e, ainda hoje, é possível perceber, em alguns, indignação quando se afirma que Gardel era francês.

9. Em seu estudo sobre as manifestações culturais que deram origem ao tango, Martinez, Etchegaray e Molinari fazem, então, uma análise da obra dos principais autores de poesia "gaucha", de Bartolomé Hidalgo, passando por Hilário Ascasubi e Estanislao del Campo, chegando até José Hernández, cujo poema "El gaucho Martín Fierro", desde 1872, teria se convertido "en la cumbre de nuestra literatura y más allá del transcurso del tiempo, es una fuente en que siguen abrevando, todavía los argentinos de todos los niveles sociales 
y culturales" (Martinez, Etchegaray e Molinari, 2000: 92). Em "Martín Fierro", a imagem forte do "gaucho" contrasta com sua absurda exclusão social. $\mathrm{O}$ tratamento dado a ele só é comparável ao dado aos nativos pelos conquistadores espanhóis. Apesar da fenomenal vendagem do livro para a época, o reconhecimento por parte das elites não foi imediato, em função, em grande medida, da visão política do autor presente em sua crítica à situação do "gaucho". Ironicamente, como apontam Martinez, Etchegaray e Molinari (2000: 101).: "Su aparición [do poema] en forma simul-

\section{Referências bibliográficas}

AMADO, Janaína. Região, sertão, nação. Estudos Históricos, Rio de Janeiro, vol. 8, n. 15, 1995, p. 145-152.

ANDERSON, Benedict. Nação e consciência nacional. São Paulo: Ática, 1989.

ARCHETTI, Eduardo P. O "gaucho", o tango, primitivismo e poder na formação da identidade nacional argentina. Mana, Rio de Janeiro, Fapesp/Museu Nacional, vol. 9, n. 1, 2003, p. 9-29.

BARSANTE, Cassio Emmanuel. Carmen Miranda. Rio de Janeiro: Europa, 1983.

BARSKY, Julian \& BARSKY, Osvaldo. Gardel. La biografia. Buenos Aires: Aguilar, Altea, Aurus, Alfaguara, 2004.

BLOCH, Marc. Pour une histoire compareé des societés européennes. In : Melanges Historiques. Paris: Sevpen, 1963.

CAPELATO, Maria Helena. Fascismo: uma ideia que circulou pela América Latina. In: História em Debate. Rio de Janeiro: Anpuh, 1991, p. 51-63. tánea con el ocaso del gaucho sirvió, paradójicamente, para que, algunos años después, muchos de los responsables de su desaparición física lo utilizaran en la reivindicación de su figura legendaria, como una bandera ante el avance de la inmigración gringa que comenzaba a preocuparlos". Neste sentido, o "gaucho" foi construído como um dos "mitos fundadores", utilizando a expressão de Chauí (2000), da identidade nacional argentina.

10. Como propõem autores como Pesavento (1999) e Santos (2000).

CARDOSO, Ciro Flamarion \& PÉREZ BRIGNOLLI, Héctor. Os métodos da história. Rio de Janeiro: Graal, 1990.

CARDOSO JUNIOR, Abel. Carmen Miranda: a cantora do Brasil. Edição particular do autor, 1978.

CHARTIER, Roger. A história cultural. Lisboa: Bertrand/Difel, 1990.

- À beira da falésia: a história entre incertezas e inquietude. Porto Alegre: EdUFRGS, 2002.

CHAUI, Marilena. Brasil: mito fundador $d a$ sociedade autoritária. São Paulo: Fundação Perseu Abramo, 2000.

COLLIER, Simon. Carlos Gardel - su vida, su música, su época. Buenos Aires: Sudamericana, 1988.

GARCIA, Tânia Costa. A canção popular e as representações do nacional no Brasil dos anos 30: a trajetória artística de Carmen Miranda. Questões e Debates, Curitiba, UFPR, ano 16, n. 31, 1999. 
-O "it verde e amarelo" de Carmen Miranda (1930-1946). São Paulo: Annablume-Fapesp, 2004.

GIL-MONTERO, Martha. Carmen Miranda: a pequena notável. Rio de Janeiro: Record, 1989.

HAUSSEN, Doris Fagundes. Rádio e politica: tempos de Vargas e Perón. Porto Alegre: EDIPUCRS, 2001.

HOBSBAWM, Eric. Nações e nacionalismo desde 1780. Rio de Janeiro: Paz e Terra, 1991.

KERBER, Alessander. Carmen Miranda entre representações da identidade nacional e de identidades regionais. ArtculturaRevista do Programa de Pós-Graduação em História da Universidade Federal de Uberlândia, Uberlândia, UFU, vol. 7, n. 10, 2005.

. Representações das identidades nacionais argentina e brasileira nas canções interpretadas por Carlos Gardel e Carmen Miranda (1917-1940). Tese (Doutorado em História) - Universidade Federal do Rio Grande do Sul, Porto Alegre, 2007.

MARTINEZ, Roberto L.; ETCHEGARAY, Natalio P. \& MOLINARI, Alejandro. De la Viguela al Fueye: las expresiones culturales argentinas que conducen al tango. Buenos Aires: Corregidor, 2000.

PARANHOS, Adalberto. Vozes dissonantes sob um regime de ordem-unida (música e trabalho no "Estado Novo"). ArtCultura, Uberlândia, UFU, vol. 4, n. 4, junho de 2002.

PELUSO, Hamlet \& VISCONTI, Eudardo. Carlos Gardel y la prensa mundial. Buenos Aires: Corrigidor, 1998.

PESAVENTO, Sandra Jatahy. O imaginário da cidade: visões literárias do urbano-Paris, Rio de Faneiro, Porto Alegre. Porto Alegre: EdUFRGS, 1999.

SANTOS, Afonso Carlos Marques dos. A cidade do Rio de Janeiro: de laboratório da civilização à cidade símbolo da nacionalidade. In: A Visão do Outro: Seminário BrasilArgentina. Brasília: Funag, 2000, p. 149174.

SILVA, Ligia Osório. Fronteira e identidade nacional. In: V Congresso Brasileiro de História Econômica, 2003. Disponível em: <http://www.abphe.org. br/congresso2003/ Textos/Abphe 2003_101.pdf>. Acesso em: 7 de janeiro de 2007.

THIESSE, Anne-Marie. Ficções criadoras: as identidades nacionais. Anos 90, Porto Alegre, UFRGS, n. 15, 2001/2002.

VELLOSO, Mônica Pimenta. As tias baianas tomam conta do pedaço - espaço e identidade cultural no Rio de Janeiro. Estudos Históricos, Rio de Janeiro, CPDOC/FGV, vol. 3, n. 6, 1990.

\section{Resumo}

No presente artigo, propõe-se uma análise das representações de identidades regionais presentes nas músicas e na imagem de Carlos Gardel e Carmen Miranda. Parte-se da hipótese de que esses dois artistas foram importantes no processo de negociação e construção das identidades nacionais brasileira e argentina. Em suas músicas, imagem e performance havia, também, representações de identidades regionais, algumas das quais foram afirmadas como nacionais. 
Palavras-chave: representações, identidades regionais, Carmen Miranda, Carlos Gardel
Abstract
In this article we intend to analyze the representations of regional identities in the songs and images of Carlos Gardel and Carmen Miranda. The hypothesis is that those artists were important in the process of negotiation and building of Argentinean and Brazilian national identities. In their songs, images and performance, there were also representations of regional identities, some of which have been taken as national ones.
Key words: representations, regional identities, Carmen Miranda, Carlos Gardel

\section{Résumé}
Cet article propose une analyse des représentations des identités régionales présentes dans la musique et l'image de Carlos Gardel et de Carmen Miranda. L'hypothèse est que ces deux artistes ont été importantes dans le processus de négociation et de construction de l'identité nationale brésilienne et argentine. Dans leur musique, l'image et la performance sont également des représentations des identités régionales, dont certaines ont été affirmées en tant qu'identités nationales.
Mots-clés: représentations, identités, Carmen Miranda, Carlos Gardel 